\title{
Municipal Street Lighting Systems Energy Cost and Carbon Footprint Estimation in Uyo, Nigeria
}

\author{
Ye-Obong Udoakah, Emmanuel Mudaheranwa and Liana Cipcigan \\ Center for Integrated Renewable Energy Generation and Supply \\ School of Engineering \\ Cardiff University \\ Cardiff, Uk \\ Udoakahyn1@cardiff.ac.uk, Mudaheranwae@cardiff.ac.uk, Cipciganlm@cardiff.ac.uk
}

\begin{abstract}
This paper analyses the energy cost and carbon emission footprint of the current street lighting systems in Uyo Nigeria. Using a life cycle assessment approach, a comparative analysis of the carbon footprints of the diesel powered system alongside the two lighting schemes namely: the High Pressure Sodium (HPS) and Light Emitting Diodes (LED) systems were examined. The analysis shows that the LED systems although having an initial high replacement cost, are the most economically viable, offering the least energy cost per annum with very minimal carbon emission footprint as opposed to the diesel powered HPS system which has both high energy cost and carbon emission footprints. Besides this, LED lighting systems when compared with HPS offers a combination of improved nighttime visibility, reduced operations/maintenance cost and decrease in carbon emission. It is hoped that the results of this study would influence municipal authorities in their choice of lighting schemes.
\end{abstract}

Index Terms - Carbon Footprint, Energy Cost, Light Emitting Diode, High Pressure Sodium, Street Lighting

\section{INTRODUCTION}

Most countries in sub-Saharan Africa are faced with several energy challenges including low energy access rate, low generating capacity, high technical and non-technical losses [1]. Nigeria, which is the largest economy in Africa, is also faced with similar challenges. Even though Nigeria has an installed capacity in excess of $12,000 \mathrm{MW}$, the operational capacity of all the generating facilities is about 6,000 MW, which is not sufficient to cater to the electricity needs of the country and often result in sporadic outages [2], [3]. Lighting is one of the basic end-uses of electricity, but the sporadic electricity outages in Nigeria has made it difficult for citizen to meet this basic need using grid-based electricity, especially at night. Consequently, most people have standby generating sets for backup power at night while some municipal authorities have resorted to the use of standby generators for municipal street lighting. This approach, though being pragmatic in addressing the challenge of providing good illumination at night, comes at a significant environmental and huge financial cost because of the diseconomies of scale in electricity generation. The use of several stand-alone diesel generators contribute significantly to the environmental pollution and greenhouse gas emissions thereby increasing the carbon footprint of the cities. In addition, the recurrent costs of the standalone generators are also relatively high.

Since lighting is one of the basic end-uses of electricity, its carbon footprint is expectedly significant. For example, [4] noted that public lighting represents a non-negligible source of $\mathrm{CO}_{2}$ emission. Similarly, the International Energy Agency (IEA) noted that lighting was responsible for about $19 \%$ of global electricity use and around $6 \%$ of global greenhouse gas emissions in 2005 [5]. An update to this information by the same Agency in 2011 noted that doubling lighting efficiency globally would have a climate impact equivalent to eliminating half the emissions of all electricity and heat production in the Europe (EU) [6]. In the United States (US), published data from market intelligence and IEA showed that cutting the energy used by lighting by $40 \%$ would save US $\$ 53$ billion in annual energy cost and reduce energy demand equivalent to $198 \mathrm{mid}$-size power stations. Furthermore, the United States Department of Energy's Municipal Solid-State Lighting Consortium estimated that the nation's streetlights consume the energy equivalent of 1.9 million households and cost \$ 6-8 billion annually for energy and maintenance [7].

Despite the prevalence of the use of generating sets for street lighting in some cities in Nigeria, there has not been any study to examine its environmental impacts. This study intends to fill this knowledge gap. In particular, the objective of this study is to examine the carbon footprints of using the standalone diesel generating sets for street lighting in many areas of the city of Uyo, Southern Nigeria and the alternatives to reducing the carbon footprints. 


\section{LITERATURE REVIEW}

Several studies have examined the carbon footprints of different economic activities such as transportation, students' behavior, airport carbon emissions, household land use or lighting systems [8]-[13]. These studies are useful in understanding the diverse approaches that may be used to estimate the carbon footprints of different socio-economic activities. For example, to estimate the carbon footprint of students of a University in China, [9] conducted a survey to obtain data on students' behavior vis-à-vis energy consumption activities. The survey covered daily activities of students and was grouped into three major categories: daily life, academics, and transportation, and 17 different subcategories. The study then employed diverse analytical models in conjunction with several conversion factors to estimate the carbon footprints of the students with respect to each activity, and thereafter estimated the carbon footprints of all the students.

In another of such study, [11] adopted a transport carbon footprint methodology to examine airport carbon emissions using the Bologna International Airport (Italy) as a case study. The study separated the total airport emissions into two main components: landside emissions and airport airside emissions. These components were further disaggregated to cover several activities in and around the airport and the unit carbon footprint was estimated on these activities. Similarly, [8] estimated the carbon footprint resulting from household use of public transport in Kolkata City of India. The study employed a sampling survey of 500 households across different income classes to obtain data on the means of transport of the households as well as other variables that may affect choice of means of transportation. The study estimated the carbon footprints based on the data obtained. Reference [13] examined the effect of urban heat island on outdoor lighting systems. The study employed a life-cycle approach which enables researchers to assess the environmental impact of goods/services by quantifying the use of resources (e.g. energy, water) in producing the goods/services and the emissions arising from the use of the goods/services throughout the lifecycle of the goods/services.

\section{METHOD}

\section{A. Study Area}

The study was conducted in Uyo (Latitude $5^{\circ} 18^{\prime} 53.7^{\prime \prime} \mathrm{N}$ ) - an emerging city in the southern part of Nigeria. The city plan of Uyo may be described as circular, in the sense that the city has major trunk roads which lead to the center and all other minor roads connect to the major roads. All the major roads are dual carriage ways and are fitted with double arm street lights at the centre. The total length of the major roads considered in this study is about $43.6 \mathrm{~km}$. The street lights for each major road are partitioned into clusters and each streetlight cluster has one stand-alone diesel generating set to power the streetlights.

\section{B. Method}

The study adopts the Life Cycle Assessment approach for estimating carbon footprints used by [13] and [14]. The methodology is typically used to quantify the environmental impact and Greenhouse Gas (GHG) emissions due to predefined activities. This involves estimating the total amount of GHG emissions resulting from an activity whether directly or indirectly. Collection of data of several activities that emit GHGs is achieved through direct onsite real-time measurements, or through estimations based on emission factors and models. Several studies have shown that emission factors and models are the most used and preferred method. The International Standards Organization [15] highlights three different methodologies used to quantify GHGs. This include: measurement, calculation and a combination of both. The objective of this study is to estimate the carbon footprints of using diesel stand-alone generating set to power street lights. Specifically, the study focuses on $\mathrm{CO}_{2}$ emission as opposed to GHG emissions. To achieve this, the Life Cycle Assessment approach for calculating emission given by British Standards Institution (BSI, 2008) [16] and (Carbon Trust and Crown (CTC, 2008) [17] as follows is adopted:

$\mathrm{CO}_{2}$ emission $=$ Activity data $(\mathrm{kg} / \mathrm{km} /$ liters $) *$ Emission factor ( $\mathrm{CO}_{2}$ per unit).

\section{Data Collection}

The activity data involves direct measurements within the life cycle of a specific product. It provides more detailed information on the activities which led to the emission. In this research study, this involves the volume of diesel used to power the streetlight in liters (L). To estimate this, secondary data on the number of street lights installed within Uyo metropolis were obtained from the street lighting monitoring unit of the state Ministry of Works. Although data were collected for all the major roads, the study selected only four roads for this research. The selection was purposive and was done to reflect certain features like the road span, frequency of usage, volume of traffic among others. Table 1 is presenting the summary of the data collected.

On the other hand, an emission factor is used to convert activity data to $\mathrm{CO}_{2}$ emissions. Secondary data on emissions factor were obtained from [17]. In this study, the $\mathrm{CO}_{2}$ emission is a result of using multiple diesel generating set to power public street lights. In determining the emission, first the carbon footprint boundary which helped to group the components of the carbon footprint for the analysis was set followed by the use of standard methods for the determination of GHG emission factors in the evaluation of fuel combustion. 
TABle 1: SumMary OF StREet Light PARAMETERS

\begin{tabular}{|c|c|c|c|c|c|}
\hline Roads & $\begin{array}{c}\text { No. of } \\
\text { Poles }\end{array}$ & $\begin{array}{c}\text { Lamp } \\
\text { Wattage } \\
\text { per Pole } \\
\text { (W) }\end{array}$ & $\begin{array}{c}\text { Total } \\
\text { Load } \\
\text { for } \\
\text { the } \\
\text { Road } \\
\text { (kW) }\end{array}$ & $\begin{array}{c}\text { No. of } \\
\text { Generators } \\
\text { per Road }\end{array}$ & $\begin{array}{c}\text { Average } \\
\text { Monthly Fuel } \\
\text { Consumption } \\
\text { per Generator } \\
\text { (L) }\end{array}$ \\
\hline Road 1 & 575 & 500 & 287.5 & 6 & 5,611 \\
\hline Road 2 & 300 & 500 & 150.0 & 7 & 6,705 \\
\hline Road 3 & 150 & 500 & 75.0 & 3 & 4,546 \\
\hline Road 4 & 192 & 500 & 96.0 & 4 & 3,702 \\
\hline
\end{tabular}

TABLE 2: CARBON EMISSION FOOTPRINT MEASUREMENT FORMULA [17]

\begin{tabular}{|c|c|c|}
\hline Variable & $\begin{array}{c}\text { Carbon Footprint } \\
\text { Formula }\end{array}$ & Notes \\
\hline Fuel & $\mathrm{CO} 2=\mathrm{AMF} * \mathrm{FEF}$ & $\begin{array}{l}\text { AMF: Average Monthly Fuel in } \\
\text { liters used } \\
\text { FEF: Fuel Emission Factor } \\
\left(\mathrm{CO}_{2} \mathrm{e} / \text { Liters }\right) \\
\text { Every liter of diesel releases } 2.8 \mathrm{~kg} \\
\text { of } \mathrm{CO}_{2}, 10.7 \mathrm{kWh} \\
\text { Of electric energy }\end{array}$ \\
\hline Electricity & $\mathrm{CO} 2=\mathrm{AME} * \mathrm{EEF}$ & $\begin{array}{l}\text { AME: Average Monthly Electricity } \\
\text { used }(\mathrm{kWh}) \\
\text { EEF: Electricity Emission Factor } \\
\left(\mathrm{CO}_{2} \mathrm{e} / \mathrm{kWh}\right) \\
\text { The EEF is }\left(0.585 \mathrm{CO}_{2} \mathrm{e} / \mathrm{mWh}\right)\end{array}$ \\
\hline
\end{tabular}

TABLE 3: CARBON FOOTPRINT OF VARIOUS FOSSIL FUELS AND RENEWABLE ENERGY SOURCES FOR THE PRODUCTION OF $1 \mathrm{KWH}$ OF ELECTRIC ENERGY

[18]

\begin{tabular}{|c|c|}
\hline \multicolumn{2}{|c|}{ Fossil Fuel } \\
\hline Fuel Type & CO $_{2}$ Footprint (lb) \\
\hline Wood & 3.306 \\
\hline Coal-fired plant & 2.117 \\
\hline Gas-fired plant & 1.915 \\
\hline Oil-fired plant* & 1.314 \\
\hline Combined-cycle gas & 0.992 \\
\hline Green and Renewable Sources \\
\hline Hydroelectric & 0.0088 \\
\hline Photovoltaic & 0.2204 \\
\hline Wind & 0.03306 \\
\hline
\end{tabular}

In addition, estimates for the carbon footprint of various fossil fuels and renewable energy sources for the production of $1 \mathrm{kWh}$ of electricity is obtained. These are presented in Tables $2 \& 3$ respectively.

\section{RESULTS AND DISCUSSIONS}

The data collected is used in conjunction with other design parameters as obtained from other secondary sources to determine the total energy consumed, the energy cost for the year, cost savings and the carbon $\left(\mathrm{CO}_{2}\right)$ footprint emitted by both the diesel powered and an equivalent PV powered systems. A comparative study was also carried out to determine which option was more economically viable.

\section{A. Energy Consumption Cost Considerations and Carbon Footprint}

From Table 1, the total number of generators used is 20 . Using the minimum number of liters $(3,702)$ consumed per month by each generator as the bench mark, it can be seen that for 20 generators, 74,040 liters of diesel are consumed monthly, which translates to 888,480 liters yearly. In monetary terms, at the current cost per liter of diesel in Nigeria, of $\$ 210$ (\$0.58) ${ }^{1}$, this amounts to $\$ 186,580,800.00$ $(\$ 515,416.58)$ annually. This excludes the cost of servicing, maintenance and repairs.

A liter of diesel contains about 38MJ of energy [19]. Similarly, 888,480 liters being the yearly diesel consumption contains $33,762,240 \mathrm{MJ}$ of energy, leading to the generation of $9,378,400 \mathrm{kWh}$ of electric energy yearly, since $1 \mathrm{kWh}$ equals $3.6 \mathrm{MJ}$ of energy.

Using equation 1 and making reference to Table 2 , the $\mathrm{CO}_{2}$ emission is computed to be $2,487,744 \mathrm{~kg}$ of $\mathrm{CO}_{2}$. This is the yearly $\mathrm{CO}_{2}$ footprint that is emitted into the atmosphere by generator powered street light activity in only four roads.

The energy used is determined from equation 2 by summing the overall wattage and multiplied by the expected hours of use as shown below:

Energy Consumed/day $=$ Total Wattage $*$ hours of usage

Using equation 2, for all the four roads, the daily and annual Energy consumed using 250W HPS and 120W LED fittings is presented in Table 4. A 12 hour daily usage period is assumed. It can be observed from Table 1 that the wattage of each lamp used for street lights is $250 \mathrm{~W}$. Studies have shown that the luminance of a $250 \mathrm{~W}$ HPS streetlight is similar to that of a $120 \mathrm{~W}$ LED lamp [7] and [13]. Therefore the amount of energy that would have been consumed if an equivalent number of LED fittings of $120 \mathrm{~W}$ were installed is examined. The daily and annual Energy saving which is the difference between the two values of HPS and LED is given as $3,797 \mathrm{kWh}$ and $1,385,919.6 \mathrm{kWh}$ respectively.

\footnotetext{
${ }^{1}$ We use the prevailing exchange rate in December, 2018 throughout the study i.e. US\$1 $=\$ 362$
} 
TABLE 4: ENERGY CONSUMPTION RESULTS

\begin{tabular}{|l|l|l|l|}
\hline S/N & \multicolumn{1}{|c|}{$\begin{array}{c}\text { Luminary } \\
\text { Type }\end{array}$} & \multicolumn{1}{|c|}{$\begin{array}{c}\text { Daily Consumption } \\
\text { (kWh) }\end{array}$} & $\begin{array}{c}\text { Annual Consumption } \\
\text { (kWh) }\end{array}$ \\
\hline 1. & HPS & 7,302 & $2,665,230$ \\
\hline 2. & LED & 3,505 & $1,279,310.4$ \\
\hline
\end{tabular}

Using the applicable parameters from Table 3, the carbon foot print is calculated from equation 3 .

Carbon Footprint $=$ Energy consumption $* \mathrm{CO}_{2}$ Footprint of fuel type

Using the energy consumption values for HPS and LED respectively, the daily and annual carbon footprint is computed from equation 3 and presented in Table 5.

TABLE 5: CARBON FOOTPRINT RESULTS

\begin{tabular}{|l|l|l|l|}
\hline S/N & \multicolumn{1}{|c|}{$\begin{array}{c}\text { Luminary } \\
\text { Type }\end{array}$} & $\begin{array}{c}\text { Daily Carbon } \\
\text { Footprint }(\mathbf{l b ~ C O} \text { C }\end{array}$ & $\begin{array}{c}\text { Annual Carbon } \\
\text { Footprint }\left(\mathbf{l b} \mathbf{C O}_{2}\right)\end{array}$ \\
\hline 1. & HPS & 9,595 & $3,502,112$ \\
\hline 2. & LED & 4,605 & $1,680,855$ \\
\hline
\end{tabular}

For the energy cost determination, it is assumed that both the HPS and LED fittings are powered using electricity supply from the grid. To determine the energy cost, equation 4 is applied.

Energy Cost $=$ Wattage $*$ hour $/ 1000 * \lambda$

Where $\lambda$ represents the $\mathrm{kWh}$ rate of electric energy. The current cost per $\mathrm{kWh}$ of electricity in Nigeria is 26.41 (\$0.073). The energy cost is presented in Table 6 .

TABLE 6: ENERGY COST

\begin{tabular}{|l|l|l|c|}
\hline S/N & \multicolumn{1}{|c|}{$\begin{array}{c}\text { Luminary } \\
\text { Type }\end{array}$} & $\begin{array}{c}\text { Daily Energy Cost } \\
\text { (A) }\end{array}$ & $\begin{array}{c}\text { Annual Energy Cost } \\
\text { (N) }\end{array}$ \\
\hline 1. & HPS & $192,845.82$ & $70,388,724.3(\$ 194,444)$ \\
\hline 2. & LED & $92,567.05$ & $33,786,587.7(\$ 93,333)$ \\
\hline
\end{tabular}

Comparing the energy cost for the diesel powered systems and the grid powered systems a large difference is obvious as highlighted below.

Diesel cost, excluding plant servicing, repairs and maintenance $=\$ 186,580,800.00(\$ 515,416.58)$. Cost of grid electricity for the same period using HPS fittings $=$ $70,388,724.3 \quad(\$ 194,444)$. This gives a difference of ¥116,192,076.00 (\$320,972.585).

Calculating the payback time of any investment requires examining the expenditure over the entire life of such system, in this case, the HPS and LED fittings. To achieve this, certain assumptions have been made. For the HPS fittings, it is assumed that the fitting components would function without defects throughout the hour life period of the HPS lamp which is about 20,000 (4.5 years). The hour life period of an LED lamp is about 60,000 (13.5 years) assuming 12 hours of usage per day.

For a $120 \mathrm{~W}$ LED, the payback time is calculated thus: in its 60,000 - hour life a 120W LED will consume 7,095.6 $\mathrm{kWh}$ from equation 2 . Using equation 4 , the energy cost for the LED $=187,395$ (\$518). Adding the unit cost of an LED fixture which is about $\$ 78,375$ (\$217) will result in a total cost over 60,000 hours of $\$ 265,770$ (\$734).

For a $250 \mathrm{~W}$ HPS, the payback time is calculated using the same procedure. In its 20,000 - hour life, the HPS will consume 4,927.5kWh and the energy cost will be 130,135 (\$359), for the first 20,000-hour life and $\$ 390,405(\$ 1,078)$ for 60,000-hour life. However, since each HPS bulb lasts for about 20,000 hours, thus for over 60,000 hours, there may be a need to replace the bulb thrice at a unit cost of $\$ 12,670$ (\$35), which adds up to $\$ 38,010$ (\$105), thus giving a total of $\$ 469,665$ (\$1,297) when added to the energy cost and fittings cost of $\$ 1,250$ (\$114). Bulb cost is assumed in this study to be constant throughout the 60,000-hour life.

A comparison of the overall unit cost of fittings and energy for the HPS and LED systems determined above over a 60,000 hours period will result in a unit gain of $\$ 203,895$ (\$563) if an LED fitting was used. This is the cash saving per unit installation besides other considerations. Multiplying this value by the number of street light poles in Table 1 and taking into consideration that each pole carries two fittings will result in a total cash savings of $496,280,430$ $(\$ 1,370,940)$.

In determining the duration for which a return on the investment would be made, the expenditure - time graph shown in Figure 1 explains this. With the initial unit cost for a 120W LED fitting of $\$ 78,375$ (\$217), with energy consumption of $1,182.6 \mathrm{kWh}$ in every 10,000 hours of use. This amounts to an electricity cost of $\$ 31,232$ (\$87) using equation 4. This will then form a geometric sequence giving the cost after 10,000 hours of use to be $\$ 78,375+\$ 31,232=$ \$109,607 (\$303). Table 7 shows the complete sequence for just one fitting.

TABLE 7: GEOMETRIC SEQUENCE OF ELECTRICITY COST FOR A 120W LED FITTING

\begin{tabular}{|l|l|l|}
\hline Hours of Use (hr) & Fitting + Cost of Electricity (\$) & $\begin{array}{c}\text { Cost of } \\
\text { Electricity } \\
\mathbf{( \$ )}\end{array}$ \\
\hline 0 & 78,375 & 217 \\
\hline 10,000 & 109,607 & 303 \\
\hline 20,000 & 140,839 & 389 \\
\hline 30,000 & 172,071 & 475 \\
\hline 40,000 & 203,303 & 562 \\
\hline 50,000 & 234,535 & 648 \\
\hline 60,000 & 265,767 & 734 \\
\hline
\end{tabular}


For HPS, the initial cost of a $250 \mathrm{~W}$ fitting is 441,250 (\$114). Just like the former, in each 10,000 hours, the electricity consumption will be $2,463.75 \mathrm{kWh}$, which costs W65,068 (\$180). In a similar pattern, the initial cost is taken to be the cost of fittings and bulb which is $\$ 53,940$ (\$149). At the end of the first 20,000 hours, the energy cost is added, a new bulb will be replaced and the expenditure will be $\$ 119,008+\$ 65,068 \$ 12,690=\$ 196,766$ (\$544). Thus after another 20,000 hours, another bulb cost will be added which adds up to $\$ 339,592$ (\$938). This continues over the 60,000 hour life period with the complete sequence shown in Table 8. The two systems are compared in the chart of Figure 1.

TABLE 8: GEOMETRIC SEQUENCE OF ELECTRICITY COST FOR A 250W HPS FITTING

\begin{tabular}{|l|l|l|}
\hline Hours of Use (hr) & Fitting + Cost of Electricity (\$) & $\begin{array}{c}\text { Cost of } \\
\text { Electricity } \mathbf{( \$ )}\end{array}$ \\
\hline 0 & 53,940 & 149 \\
\hline 10,000 & 119,008 & 329 \\
\hline 20,000 & 196,766 & 544 \\
\hline 30,000 & 261,834 & 723 \\
\hline 40,000 & 339,592 & 938 \\
\hline 50,000 & 404,660 & 1,117 \\
\hline 60,000 & 469,728 & 1,298 \\
\hline
\end{tabular}

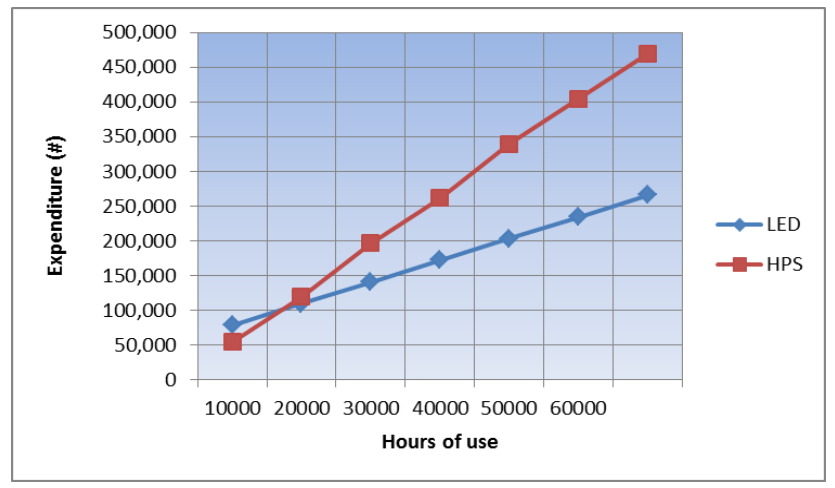

Figure 1. Expenditure-time chart for LED and HPS

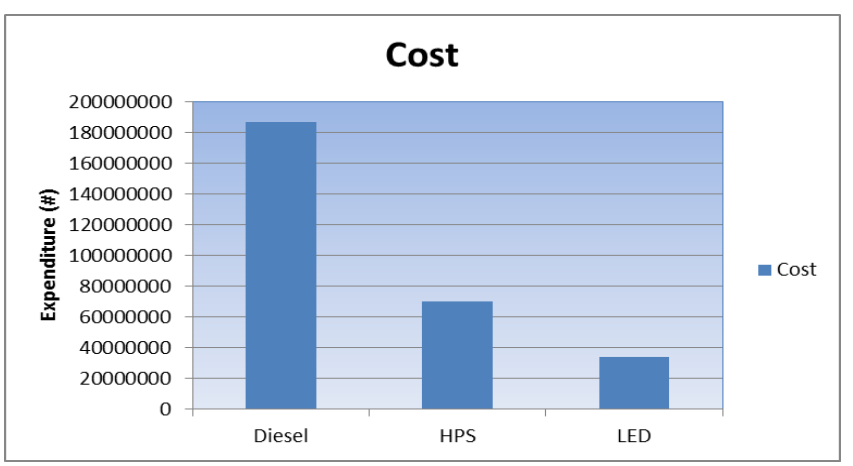

Figure 2. Annual diesel expenditure and energy cost chart for HPS and LED fittings

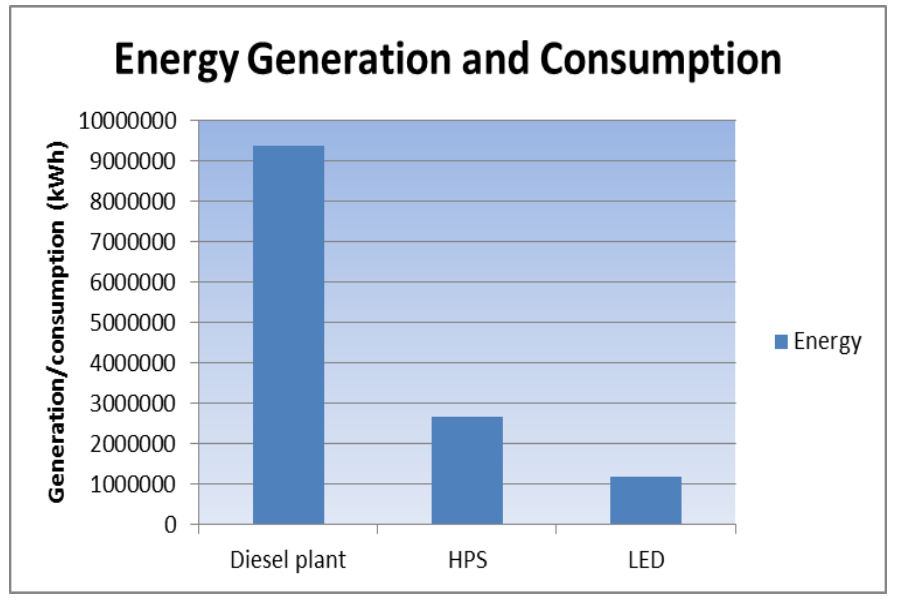

Figure 3. Annual energy generation and consumption chart for LED and HPS

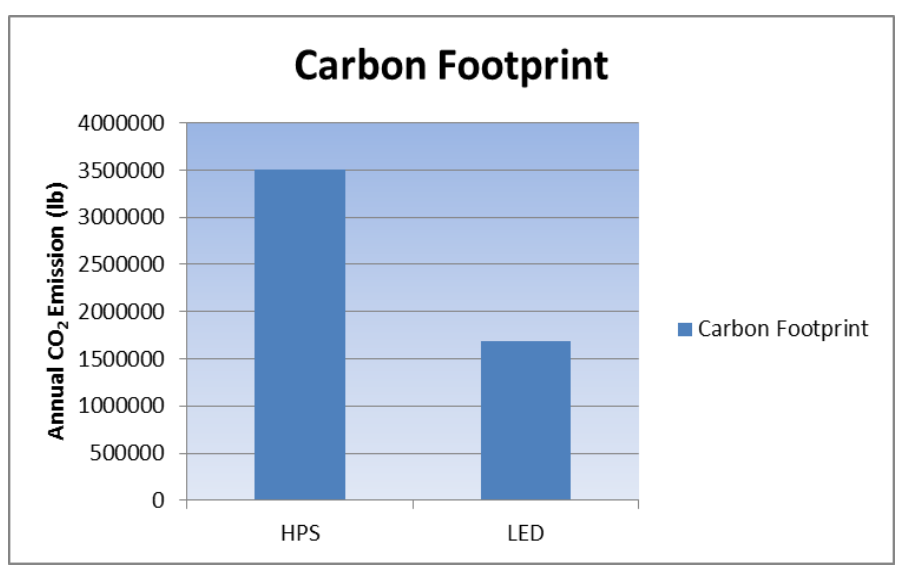

Figure 4. Carbon emission chart for diesel powered HPS lamp and LED lamp

In Figure 2, the annual diesel cost together with the energy cost for both the HPS and LED fittings assuming it was powered from the grid at the cost per kWh of \#26.41 (\$0.073) for electricity in Nigeria is compared. From the chart, it is seen that the annual diesel cost is quite high compared to the cost of powering the HPS and LED system with grid electricity. However, with grid electricity, the cost of powering the LED systems is about half of the HPS system, thus making the LED system to be the best alternative. In Figure 3 , the annual energy generation by the diesel power plant and the energy consumed using 250W HPS and $120 \mathrm{~W}$ LED lamps are compared. Again, the annual energy consumption of the LED fitting is far less than that of the HPS fitting, making it a more sustainable option. The annual $\mathrm{CO}_{2}$ footprint of the diesel power powered HPS lamps and solar LED systems powered for 4,380 hours is compared in Figure 4. The difference in the $\mathrm{CO}_{2}$ footprint emission is quite clear with that emitted by the diesel powered system being outrageously high while that emitted by the LED lamp could be considered to be not quite significant. 


\section{CONCLUSION}

No doubt, the energy conservation and awareness created by new LED lighting technologies is becoming a more predominant trend globally and has prompted the need for a lighting revolution. As was illustrated in the analysis, the life span of an LED street light is about 60,000 hours, which is equivalent to almost six and a half years of continuous operation which equate to about 13 years of life when in operation for 12 hours. From the analysis, it can be concluded that by transitioning to an LED system, there will be an increase in energy savings and decrease in energy bill, resulting in a significant decrease of the overall system cost. Also, with a projected lifespan of about 60,000 hours, the replacement and maintenance cost is greatly reduced, thus enhancing additional operational savings. More so, the carbon footprints of LED lights are quite insignificant since they are $100 \%$ recyclable and contain no toxic materials compared to the conventional HPS conventional street lights. Finally, it is hoped that the result of the analysis will be used by the municipal authorities in taking key policy decisions with regards to the choice of street lighting schemes.

For future works, the scope of the study would be expanded to include an assessment of the energy payback time of grid connected, generator connected and photovoltaic (PV) powered street lighting systems. The prevailing discount and interest rates would be used for the analysis with due consideration given to the possible failure rates of the three systems.

\section{ACKNOWLEDGMENT}

The authors gratefully acknowledge the contributions of Uduak Akpan of SPIDER Solutions Nigeria Limited. Your suggestions and inputs have been quite valuable. Also we are thankful to the street light monitoring unit of Akwa Ibom State Ministry of Works, for allowing us access to street light data used in this research. To the students who helped in physically verifying the street lights parameters obtained for all the roads, we say thank you. Lastly, I appreciate and acknowledge TETFund Nigeria for the sponsorship.

\section{REFERENCES}

[1] V. Foster and C. Briceño-Garmendia, "Africa's Infrastructure: A Time for Transformation," Retrieved September 29, 2018, from http://www.infrastructureafrica.org/system/files/Africa's\%20Infrastruct ure $\% 20 \mathrm{~A} \% 20$ Time $\% 20$ for\%20Transformation\%20FULL\%20TEXT.20 10 pdf.
[2] Y. Udoakah and M. Umoh, "Sustainably Meeting the Energy Needs of Nigeria: The Renewable Options," in proc. 2014 IEEE Energycon Conf., pp. 326-332.

[3] U. Akpan, "Technology Options for Increasing Electricity Access in Areas with Low Electricity Access Rate in Nigeria," Socio-economic Planning Sciences , 51, pp. 1 - 12, 2015.

[4] D. Radulovic, S. Skok, and V. Kirincic, "Energy efficiency public lighting management in the cities," Energy , 36, pp. 1908-1915, 2011.

[5] IEA, "Light's Labour's Cost," Retrieved October 9, 2018, from International Energy Agency: http://www.iea.org/publications/freepublications/publication/light2006. pdf

[6] IEA, "25 Energy Efficient Policy Recommendations," Retrieved October 9, 2018, from International Energy Agency: http://www.iea.org/publications/freepublications/publication/energy201 1.pdf

[7] TL Energy, "Illuminating the Benefits of LED Street Lights," Retrieved September 29, 2018, from http://www.trans-lux.com/wpcontent/uploads/2013/02/Trans-Lux-Energy-LED-Lighting-WhitePaper.pdf

[8] M. D. Gupta, "Carbon footprint from road transport use in Kolkata city," Transportation Research Part D , 32, pp. 397-410, 2014.

[9] X. Li, H. Tan, and A. Rackes, "Carbon footprint analysis of student behavior for a sustainable university campus in China," Journal of Cleaner Production, 106, pp. 97 -108, 2015.

[10] W. K. Biswas, "Carbon footprint and embodied energy consumption assessment of building construction works in Western Australia," International Journal of Sustainable Built Environment , 3, pp. 179186, 2014.

[11] M. N. Postorino, and L. Mantecchini, "A transport carbon footprint methodology to assess airport carbon emissions," Journal of Air Transport Management, 37, pp. 76 - 86, 2014.

[12] S. Zubelzu, R. Álvarez, and A. Hernández, "Methodology to calculate the carbon footprint of household land use in the urban planning stage," Land Use Policy, 48, pp. 223-235, 2015.

[13] F. Rossi, E. Bonamente, A. Nicolini, E, Anderini, and F. Cotana, "A carbon footprint and energy consumption assessment methodology for UHI-affected lighting systems in built areas," Energy and Buildings, 114, pp. 96-103, 2016.

[14] M. W. Strohbach, E. Arnold, and D. Haase, "The carbon footprint of urban green space-A life cycle approach," Landscape and Urban Planning, 104, pp. 220-229, 2012.

[15] International Standards Organization, "Specification with guidance at the organizational level for quantification and reporting of greenhouse gas emission and removal 2006". Retrieved September 29, 2018, from https://www.hkctc.gov.hk/en/doc/170301_PartII-MsRebeccaWong.pdf

[16] BSI. PAS 2050:2008. Specification for the assessment of the life cycle greenhouse gas emissions of goods and services, 2008. Retrieved September 29, 2018, from http://shop.bsigroup.com/upload/shop/download/pas/pas2050.pdf

[17] Carbon Trust and Crown, "Guide to PAS 2050. How to assess the carbon footprint of goods and services," 2008. Retrieved September 29, 2018, from https://aggiehorticulture.tamu.edu/faculty/hall/publications/PAS2050_Guide.pdf

[18] A. Keyhani, Design of smart power grid renewable energy systems. New Jersey: Wiley \& Sons, Inc. 2011.

[19] G. Boyle, B. Everett, and J. Ramage, Energy Systems and Sustainability. New York: Oxford University Press Inc. 2003. 